\title{
Transactional Analysis (TA): A Learning-Teaching Tool for Faculty Development
}

\author{
Marina Rajan Joseph ${ }^{1}$, Thomas V. Chacko ${ }^{2}$
}

\section{Context and setting}

Faculty development programs are mandatory in medical colleges in India. However, often these are basic workshops to orient medical colleges to principles of pedagogy and student assessment. It is also necessary to empower teachers with skills to bring about a facilitative teaching-learning environment. A survey was conducted among medical students to find out their perceptions about the existing teachinglearning environment at the Malankara Orthodox Syrian Church Medical College, India. It revealed that students are scared of their teachers and many feel their teachers are unkind and do not understand them. Finding ways to change this situation is expected to improve teacher student relationship, which is of key importance in the learning environment.

Educational psychology forms the basis of many activities in faculty development. Transactional Analysis (TA) is a theory of personality development with educational applications. TA describes the structure of personality (Egostate model), how people communicate with each other, and also offers explanation of motivation behind human behavioural patterns. Practicing self awareness using this model develops awareness of intrapersonal and interpersonal processes. Awareness of self motivations and behaviours helps to modify self behaviour for better relationships.

\footnotetext{
${ }^{1}$ Malankara Orthodox Syrian Church Medical College, Kolenchery, Kerala, India

${ }^{2}$ PSG-FAIMER Regional Institute, PSG Medical College, Coimbatore, India

Corresponding author:

Professor Marina Rajan Joseph,

Malankara Orthodox Syrian Church Medical College,

Kolenchery, Kerala Pin 682311, India

Email: marina.rajan@gmail.com
}

\section{What was done?}

The first author, an authorized trainer in Educational Transactional Analysis conducted a course in TA for faculty members who volunteered.

Two other colleagues trained in TA evaluated the participants and gave concurrent feedback on the trainer's behaviour. The course was 'contractual' (negotiating between the expectations of participants and what the trainer got to offer) and used 'open honest transactions' (objectively stating what is expected \& giving descriptive feedback) the two TA practice principles.

Structure of personality, functional fluency model, a functional styles model in TA, rules of communication and stroke theory on motivation ('stimulation' is essential for health; 'recognitions'(stroking) substitute for physical stimulation; sometimes persons seek negative recognitions to affirm their existence) were taught to the participants with examples from the medical education scenario. The course was experiential with exercises and practice sessions. Student's perceptions and suggestions (teachers must be friendlier: teach interactively: share practical experience) were communicated to the teachers.

Self-assessment of the participant's 'awareness' in 18 areas of interpersonal relations before training, one immediately thereafter, one after three months and one a year after the training program was collected using a retro-pre behaviour assessment tool. 'Awareness' in different areas was summed and meant improvement in 'self awareness' about intrapersonal and interpersonal processes. It was calculated into a percentage. Structured pre and post tests were expected to reveal their overall learning and consensus of the participants on the usefulness of the tools. 


\section{Results}

Nineteen faculty members participated in the intervention. The mean improved in self awareness immediately after training. It was 13.36\% (CL-9.3-17.2). This remained similar three months and one year after training with no statistically significant difference. Highest improvement in awareness was in the area 'being aware of my reaction to the behaviour of others'. During the discussions, participants connected needs expressed by students, to the stroke theory on motivation. They also identified lack of positive stroking in the medical education scenario as a probable reason for lack of motivation among many students, From the various TA tools, participants identified "Positive Stroking" and "Open Honest Transactions" as the most practical TA tools for improving teacherstudent relationships. Consensus index for the practical usefulness of the tool 'Egostate model for improving self-awareness' was $88.7 \%$, The usefulness of the "functional fluency model for practicing flexibility" was $84.8 \%$. The overall usefulness of "TA tools for improving teacher student relationship" was $81.2 \%$.

\section{Conclusion and Recommendations}

The results suggested that in addition to the usual basic medical education workshops, additional inputs through structured TA programs for faculty, if conducted for all faculty regularly with opportunity for peer discussions and clinical supervision may improve personal 'awareness' of self behaviour, and interpersonal processes among teachers leading to professionalism in relationships and a better learning environment. 